\title{
Mathematical performance in childhood and early adult outcomes after very preterm birth: an individual participant data meta-analysis
}

\author{
JULIA JAEKEL ${ }^{1,2,3,4}$ (D) | PETER J ANDERSON ${ }^{5,6}$ | PETER BARTMANN ${ }^{7}$ | JEANIE L Y CHEONG CH, $^{6,9}$ | \\ LEX W DOYLE ${ }^{6,8,9}$ | MAUREEN HACK ${ }^{10, \dagger}$ | SAMANTHA JOHNSON ${ }^{4}$ | NEIL MARLOW ${ }^{11}$ (iD | SAROJ SAIGAL ${ }^{12}$ | \\ LOUIS SCHMIDT ${ }^{13}$ | MARY C SULLIVAN ${ }^{14}$ | DIETER WOLKE ${ }^{2,15}$
}

\begin{abstract}
1 Psychology, University of Oulu, Oulu, Finland. 2 Psychology, University of Warwick, Coventry, UK. 3 Child and Family Studies/Psychology, University of Tennessee Knoxville, Knoxville, TN, USA. 4 Department of Health Sciences, University of Leicester, Leicester, UK. 5 Turner Institute for Brain \& Mental Health, School of Psychology Sciences, Monash University, Melbourne, VIC, Australia. 6 Clinical Sciences, Murdoch Children's Research Institute, Melbourne, VIC, Australia. 7 Children's Hospital, University Hospital Bonn, Bonn, Germany. 8 Obstetrics and Gynaecology, University of Melbourne, Melbourne, VIC, Australia. 9 Neonatal Services, Royal Women's Hospital, Melbourne, VIC, Australia. 10 Neonatology, Case Western Reserve University School of Medicine, Cleveland, OH, USA. 11 EGA Institute for Women's Health, University College London, London, UK. 12 Pediatrics, McMaster University, Hamilton, ON, USA. 13 Department of Psychology, Neuroscience \& Behaviour, McMaster University, Hamilton, ON, Canada. 14 College of Nursing, University of Rhode Island, Providence, RI, USA. 15 Warwick Medical School, University of Warwick, Coventry, UK.
\end{abstract}

Correspondence to Julia Jaekel, Psychology, University of Oulu, PO Box 8000, FI-90014 OULUN YLIOPISTO, Oulu, Finland. E-mail: julia.jaekel@oulu.fi

${ }^{\dagger}$ Deceased.

PUBLICATION DATA
Accepted for publication 12th Novem
2021.
Published online
ABBREVIATIONS
APIC Adults born Preterm
IPD International Collaboration

Preterm birth has life-course consequences, in particular for the smallest infants and those born very preterm. Globally, about $1 \%$ to $2 \%$ of all infants are born at less than 32 weeks' gestation every year. ${ }^{1}$ Improved neonatal care has led to increased survival rates for these infants, ${ }^{2}$ but the high prevalence of cognitive and learning problems in surviving infants has not substantially changed over the last two decades. ${ }^{3,4}$ Children born very preterm $(<32$ wks' gestation or $<1500 \mathrm{~g}$ birthweight) have an increased risk for poorer academic attainment than their term-born peers, especially in mathematics. ${ }^{5-8}$ This risk persists into adolescence $^{9}$ and may diminish life-long opportunities, contributing to the frequently observed lower rates of postsecondary education and higher rates of unemployment in preterm cohorts. ${ }^{10}$ Longitudinal outcome studies in adulthood consistently show that problems of cognition, neurodevelopment, and academic achievement continue over the life- course. ${ }^{11-15}$ In addition to single cohort studies and literature-based reviews, two studies have documented considerable temporal and cross-national consistency in cognitive and mathematics performance among children born very preterm. ${ }^{16,17}$ However, it is unclear whether difficulties in mathematics among children born very preterm are accounted for by low $\mathrm{IQ}^{5}$ or not. ${ }^{7,18}$

Among general population studies, mathematics skills in childhood have independent positive effects on adult economic success. ${ }^{19,20}$ However, individuals born very preterm often experience severe medical complications and subsequent neurocognitive difficulties. ${ }^{21-23}$ Accordingly, studies in children and adults born very preterm have documented a higher prevalence of deficits in general cognitive performance in conjunction with poorer mathematics attainment than in term-born controls. ${ }^{24}$ One prospective longitudinal study of individuals born very preterm to 26 years of age 
investigated the extent to which mathematics performance in childhood explained adult economic success, but found no direct nor indirect effects after controlling for IQ. ${ }^{25}$ However, limitations of many follow-up studies into adulthood include attrition and relatively small samples, reducing statistical power.

Over and above IQ and mathematics performance, maternal education/family socioeconomic status is associated with long-term educational attainment, employment success, and wealth in adulthood. ${ }^{10,20,26,27}$ In addition, general population studies consistently report that females outperform males in school. ${ }^{28}$ For example, the life-course Panel Study of Income Dynamics found that females, on average, completed more years of schooling ${ }^{26}$ while males, on average, had higher annual incomes. ${ }^{26}$ Evidence for sex differences in life-course trajectories among individuals born very preterm is still limited, but there is emerging evidence of males being more affected by preterm birth than females with regard to educational attainment. ${ }^{29}$

In this study we aimed to determine the strength of the independent associations between mathematics performance in children born very preterm and two adult outcomes - postsecondary education and being employed or in education-while adjusting for year of birth, gestational age, sex, maternal education, and child IQ.

\section{METHOD}

This study was registered as an individual participant data (IPD) meta-analysis with the International Prospective Register of Systematic Reviews PROSPERO (protocol \#CRD42020175032).

\section{Search strategy and study selection criteria}

A two-step process was applied to identify and select studies for inclusion. First, members of the Adults born Preterm International Collaboration (APIC; www.apicpreterm.org) were presented with the study protocol. APIC is a collaborative group of international researchers who study life-course outcomes of individuals born very preterm. All APIC members were invited to contribute data to this study. Prospective longitudinal studies that had assessed participants born very preterm with standardized intelligence and mathematics tests in middle childhood and with adult data on postsecondary education and employment/education status were eligible for inclusion. Only studies with data available from at least three timepoints (i.e., birth, childhood, and adulthood) that included a contemporaneous comparison group of children born at term for the childhood assessments were included in the data harmonization and pooling process. There was no restriction for year of birth. A total of six APIC cohort studies were identified through this process by June 2019. Second, a systematic literature search was conducted in English in PubMed and PsycINFO using the keywords 'very low birth weight' OR ('very preterm' OR 'premature*' OR 'gestation*') AND ('math*' OR 'arithmetic') AND ('intelligence' OR 'IQ' OR 'cognitive') AND ('adult*').
What this paper adds

- Mathematics performance of children born very preterm is associated with educational attainment.

- Mathematics performance of children born very preterm does not predict employment status.

- I0 of children born very preterm is associated with educational attainment and employment.

- There is substantial variation between preterm cohorts, world regions, and birth epochs.

Screening and review of articles did not identify additional data sets that fulfilled the eligibility criteria. Accordingly, data from the following six birth cohorts were included in this study (ordered alphabetically by country).

\section{Australia}

The Victorian Infant Collaborative Study included all livebirths less than $1000 \mathrm{~g}$ and/or less than 28 weeks' gestational age in the state of Victoria in 1991 to 1992 and a normal birthweight $(>2500 \mathrm{~g})$ term comparison group recruited in the newborn period. ${ }^{3}$ At 8 years of age, mathematics performance was assessed using the Wide Range Achievement Test, Third Edition, Arithmetic scale, ${ }^{30}$ and IQ using the Wechsler Intelligence Scale for Children, Third Edition. ${ }^{31}$ Adult assessments were carried out at 18 and 25 years of age. ${ }^{32}$

\section{Canada}

The McMaster University Study included all livebirths weighing $1000 \mathrm{~g}$ or less in the Central-West Ontario region from 1977 to 1982, and a normal birthweight term comparison group recruited at school age. ${ }^{33}$ At 8 years of age, children were evaluated using the Wide Range Achievement Test Arithmetic scale ${ }^{30}$ and the Wechsler Intelligence Scale for Children - Revised. ${ }^{34}$ Adult assessments were carried out at 29 years of age..$^{14,35}$

\section{Germany}

The Bavarian Longitudinal Study included all livebirths born very preterm in Southern Bavaria in 1985 and 1986 and a normal birthweight term comparison group. ${ }^{36}$ At 8 years of age, children were evaluated using a standardized Mathematic Test ${ }^{5,37}$ and the Kaufman Assessment Battery for Children Mental Processing Composite scale (IQ-equivalent). ${ }^{38}$ Adult assessments were carried out at 26 years of age. ${ }^{39}$

\section{UK and Republic of Ireland}

The EPICure study is a nationwide study comprising all infants born at 22 to 25 completed weeks of gestation in the UK and Republic of Ireland between March and December 1995, and a term-born comparison group of peers recruited at school age. ${ }^{40,41}$ At 11 years of age, children were evaluated using the Wechsler Individual Achievement Test Second UK Edition Mathematics Composite scale ${ }^{42}$ and the Kaufman Assessment Battery for Children Mental Processing Composite scale (IQ). ${ }^{38}$ Adult assessments were carried out at 19 years of age. ${ }^{43}$ 
USA

The Case Western Reserve University Cohort Study included all infants with birthweights less than $1500 \mathrm{~g}$ admitted to Rainbow Babies and Children's Hospital in Cleveland from 1977 to 1979 and a normal birthweight comparison group recruited at age 8 years. ${ }^{44}$ At 8 years of age, children were evaluated using the Woodcock-Johnson Achievement Test Mathematics Scale ${ }^{45}$ and the Wechsler Intelligence Scale for Children - Revised. ${ }^{34}$ Adult assessments were carried out at 20 years of age. ${ }^{44}$

\section{USA}

The Rhode Island Cohort of Adults Born Preterm Study included livebirths weighing less than $1500 \mathrm{~g}$ in the specialty hospital from 1985 to 1989 and a 'healthy' termborn comparison group. ${ }^{46,47}$ At 8 years of age, children were evaluated using the Wide Range Achievement Test, Third Edition, Arithmetic scale ${ }^{30}$ and the Wechsler Intelligence Scale for Children, Third Edition. ${ }^{31}$ Adult assessments were carried out at 23 years of age. ${ }^{48}$

\section{Data extraction, harmonization, and analysis}

Participating groups $(n=6)$ obtained ethical permission and completed a data sharing agreement with the University of Tennessee Knoxville to transfer non-identifiable individual level data for the analysis. Groups were requested to provide neonatal data (i.e., infant gestational age at birth [wks], birthweight [g], sex [binary coded], maternal education), childhood IQ and mathematics test results (standard scores), and adult employment and educational attainment information.

Data were harmonized in SPSS v24 (IBM Corp., Armonk, NY, USA), including a variable for each cohort's year of birth. The content of the IQ and mathematics tests (e.g., dimensions assessed) were compared to confirm that these generally targeted very similar domains (see Table 1, online supporting information, for details). Test scores were $z$-standardized according to each cohort-specific contemporaneous comparison group before pooling. In line with an adaptive approach to scoring test performance, participants with IQ scores more than 2 SD below the control participants' mean (i.e., <-2 SD) were coded as having intellectual impairment. Information about maternal education was recoded into an interval-scaled 9-level variable according to the International Standard Classification of Education. ${ }^{49}$ The two dependent variables in young adulthood (i.e., 19-29y) were binary-coded as 'any postsecondary education' (1=yes, $\geq$ International Standard Classification of Education level 5 and $0=$ no, $<$ International Standard Classification of Education level 5) and 'currently employed or in education' $(1=\mathrm{yes} / 0=\mathrm{no})$.

One-stage IPD meta-analyses were performed as mixed effects logistic regressions in Stata 16 (StataCorp, College Station, TX, USA). All models were controlled for fixed effects of cohort year of birth, infant gestational age at birth, sex, maternal education, and childhood IQ, as well as the nestedness of data in cohorts (i.e., including a random effect for study site). The fixed and random effects of childhood mathematics scores on postsecondary education and being employed/in education in young adulthood are reported. Including random effects allowed for different relationships with adult outcomes within cohorts. As part of a stepwise process, random effects of other covariates were additionally included, and model fit was evaluated using log-likelihood goodness of fit tests. Random effects were retained if their inclusion significantly improved overall model fit. Specifically, with regard to attending postsecondary education, the additional inclusion of random effects for gestation and IQ improved model fit, indicated by a significant log-likelihood ratio $\chi^{2}$ test $\left(\chi^{2}[4]\right.$ =26.30, $p<0.001)$, fixed effects remained stable. With regard to being employed/in education, the additional inclusion of other covariates' random effects did not improve model fit, indicated by a non-significant loglikelihood ratio $\chi^{2}$ test $\left(\chi^{2}[4]=9.11, p=0.058\right)$.

\section{RESULTS}

Individual cohort sample sizes ranged from 117 to 231 participants (Table 1). Sex was equally distributed across study cohorts but there was substantial variation with regard to gestational age and birthweight, because of different cohort inclusion criteria, and in distributions of maternal education levels. Mean childhood IQ and mathematics z-scores ranged from -1.57 to -0.36 and -1.55 to -0.51 , respectively. Across cohorts there was variation in the proportion of adults who had attended postsecondary education (18$57 \%)$ and in those employed or in education at the time of assessment (71-88\%).

\section{One-stage IPD meta-analyses}

Mixed effects logistic regression indicated substantial heterogeneity between study cohorts (i.e., significant log-likelihood $\chi^{2}$ tests), supporting the use of mixed effects models as opposed to logistic models without random effects.

Table 2 shows that adults born very preterm with higher mathematics test scores in childhood had higher odds to have attended any postsecondary education (fixed effect odds ratio [OR] per $\mathrm{SD}$ increase in mathematics test scores: 1.36 [95\% confidence interval $\{\mathrm{CI}\}$ : $1.03,1.79]$ ). The random effect of mathematics was estimated at SD 0.21 (95\% CI: $0.05,0.82$ ), indicating significant variation between cohorts in the relationship between these two variables. In addition, adults born very preterm with higher childhood IQ (OR per SD increase in IQ: 1.58 [95\% CI: $1.26,1.97]$ ), higher educated mothers (OR per SD increase in maternal education: 1.29 [95\% CI: 1.09, 1.53]), and females (OR: 2.00 [95\% CI: 1.43, 2.78]) had higher odds to have attended postsecondary education.

The fixed effect of childhood mathematics test scores (OR=1.14 [95\% CI: 0.87, 1.48]) on current employment/ education status was not significant, while the random effect was estimated at SD 0.21 (95\% CI: 0.09, 0.51), indicating significant variation in this relationship between cohorts. Adults with higher childhood IQ were more likely 


\begin{tabular}{|c|c|c|c|c|c|c|}
\hline & $\begin{array}{l}\text { Australia } \\
\text { (Victoria; } n=166 \text { ) }\end{array}$ & $\begin{array}{l}\text { Canada } \\
\text { (McMaster; } n=122 \text { ) }\end{array}$ & $\begin{array}{l}\text { Germany } \\
\text { (BLS; } n=201 \text { ) }\end{array}$ & $\begin{array}{l}\text { UK } \\
\text { (EPICure; } n=117 \text { ) }\end{array}$ & $\begin{array}{l}\text { USA } \\
\text { (Cleveland; } n=231 \text { ) }\end{array}$ & $\begin{array}{l}\text { USA (Rhode } \\
\text { Island; } n=117 \text { ) }\end{array}$ \\
\hline Recruitment criteria & $\begin{array}{l}<28 w k s \mathrm{GA} / \\
<1000 \mathrm{~g} \mathrm{BW}\end{array}$ & $<1001 \mathrm{~g} \mathrm{BW}$ & $\begin{array}{l}<32 \text { wks GA/ } \\
<1500 \text { g BW }\end{array}$ & $22-25 w k s$ GA & $<1500 \mathrm{~g} \mathrm{BW}$ & $<1500 \mathrm{~g} \mathrm{BW}$ \\
\hline Year(s) of birth & $1991-2$ & $1977-82$ & $1985-6$ & 1995 & 1977-9 & $1985-9$ \\
\hline Female & $55.4 \%$ & $53.3 \%$ & $46.8 \%$ & $55.6 \%$ & $51.5 \%$ & $55.6 \%$ \\
\hline Birthweight (g) & 885 (155) & $841(121)$ & $1341(324)$ & $742(126)$ & $1177(219)$ & $1251(329)$ \\
\hline Gestation (wks) & $26.7(2.0)$ & $27.0(2.2)$ & $30.6(2.2)$ & $24.4(0.76)$ & $30.2(2.3)$ & $30.0(2.55)$ \\
\hline $\begin{array}{l}\text { Mother's } \\
\text { education }^{a}\end{array}$ & $3.15(0.87)$ & $3.12(1.26)$ & $3.02(1.08)$ & $2.99(0.99)$ & $2.92(0.74)$ & $4.03(1.12)$ \\
\hline $\begin{array}{l}\text { Child assessment } \\
\text { age }\end{array}$ & $8 y$ & $8 y$ & $8 y$ & $11 y$ & $8 y$ & $8 y$ \\
\hline Childhood math ${ }^{b}$ & $-0.62(1.05)$ & $-0.90(1.23)$ & $-0.74(1.15)$ & $-1.55(1.35)$ & $-0.51(1.46)$ & $-0.57(1.03)$ \\
\hline Childhood $10^{\mathrm{b}}$ & $-0.51(1.14)$ & $-0.95(1.24)$ & $-0.72(1.33)$ & $-1.57(1.44)$ & $-0.36(1.15)$ & $-0.59(1.28)$ \\
\hline $1 \mathrm{O}<-2 S D^{b}$ & $8.4 \%$ & $18.9 \%$ & $12.9 \%$ & $35.0 \%$ & $0.0 \%$ & $12.0 \%$ \\
\hline $\begin{array}{l}\text { Adult assessment } \\
\text { age }\end{array}$ & $25 y$ & $29 y$ & $26 y$ & $19 y$ & $20 y$ & $23 y$ \\
\hline $\begin{array}{l}\text { Employed/in } \\
\text { education }\end{array}$ & $78.3 \%$ & $77.0 \%$ & $87.6 \%$ & $85.5 \%$ & $80.5 \%$ & $70.9 \%$ \\
\hline $\begin{array}{l}\text { Postsecondary } \\
\text { education }^{c}\end{array}$ & $56.6 \%$ of $n=143$ & $39.1 \%$ of $n=64$ & $17.9 \%$ of $n=201$ & $25.2 \%$ of $n=111$ & $36.4 \%$ of $n=231$ & $38.8 \%$ of $n=116$ \\
\hline
\end{tabular}

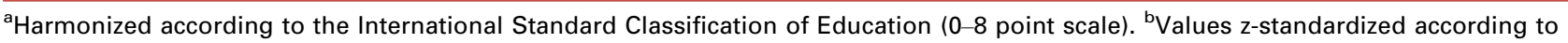
cohort-specific controls. ${ }^{\mathrm{c}}$ Proportion of participants who attended any postsecondary education (International Standard Classification of Education levels 5-8), binary coded yes/no; $n=88$ participants across different cohorts were still attending secondary education and/or did not have information about postsecondary education; the resulting total number of participants for this part of the analyses was 866 . BLS, Bavarian Longitudinal Study; GA, gestational age at birth; BW, birthweight.

\begin{tabular}{|c|c|c|}
\hline Dependent variable & $\begin{array}{l}\text { Postsecondary education ( } n=866) \\
\text { OR }(95 \% \mathrm{Cl})\end{array}$ & $\begin{array}{l}\text { Employed/in education }(n=954) \\
\text { OR }(95 \% \mathrm{Cl})\end{array}$ \\
\hline \multicolumn{3}{|l|}{ Fixed effects } \\
\hline Mathematics (per SD) & $1.36(1.03,1.79)^{\mathrm{a}}$ & $1.14(0.87,1.48)$ \\
\hline Year of birth (per year) & $1.05(0.97,1.13)$ & $1.00(0.96,1.03)$ \\
\hline Gestation (per week) & $1.06(0.98,1.15)$ & $0.97(0.90,1.03)$ \\
\hline Female & $2.00(1.43,2.78)^{\mathrm{c}}$ & $0.83(0.59,1.16)$ \\
\hline Mother's education (per point) & $1.29(1.09,1.53)^{\mathrm{b}}$ & $1.14(0.96,1.35)$ \\
\hline Participant IQ (per SD) & $1.58(1.26,1.97)^{\mathrm{c}}$ & $1.28(1.06,1.56)^{\mathrm{b}}$ \\
\hline \multicolumn{3}{|l|}{ Random effects by cohort } \\
\hline SD (Mathematics) & $0.21(0.05,0.82)$ & $0.21(0.09,0.51)$ \\
\hline SD (Gestation) & $0.02(0.01,0.04)$ & 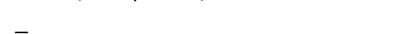 \\
\hline SD (IQ) & $0.10(0.00,4.11)$ & - \\
\hline Log-likelihood & -455.04 & -450.93 \\
\hline
\end{tabular}

For fixed effects: ${ }^{\mathrm{a}} p<0.05 ;{ }^{\mathrm{b}} p<0.01 ;{ }^{\mathrm{c}} p<0.001$. OR, odds ratio; $\mathrm{Cl}$, confidence interval; SD, standard deviation.

to be employed or in education at follow-up $(\mathrm{OR}=1.28$ [95\% CI: 1.06, 1.56]). Figure 1 displays forest plots of the effects of childhood mathematics scores on postsecondary education and current employment/education status by cohort.

As sensitivity analyses, calculations were repeated three times. First, to test the effects of mathematics test scores on adult outcomes without including control variables. These showed similar but stronger associations of mathematics performance with both postsecondary education and current employment/education status (see Table S2, online supporting information). Second, because 118 participants had intellectual impairment, models were rerun after their exclusion, again with similar findings (see Table S3, online supporting information). Finally, considering potential outlier effects of the EPICure study data indicated in Figure 1 , analyses were rerun without these 117 EPICure participants. In these models, the fixed effect of childhood mathematics test scores on attending postsecondary education (OR=1.18 [95\% CI: 0.87, 1.61]) was not significant, nor was the effect on current employment/education status (OR=1.11 [95\% CI: 0.90, 1.38]).

\section{DISCUSSION}

In this IPD meta-analysis of six very preterm cohort studies from five different countries in Europe, North America, and Australia, born between 1977 and 1995, we found evidence that higher mathematics scores in childhood were independently associated with attending any postsecondary education. Evidence was weak for an independent association 


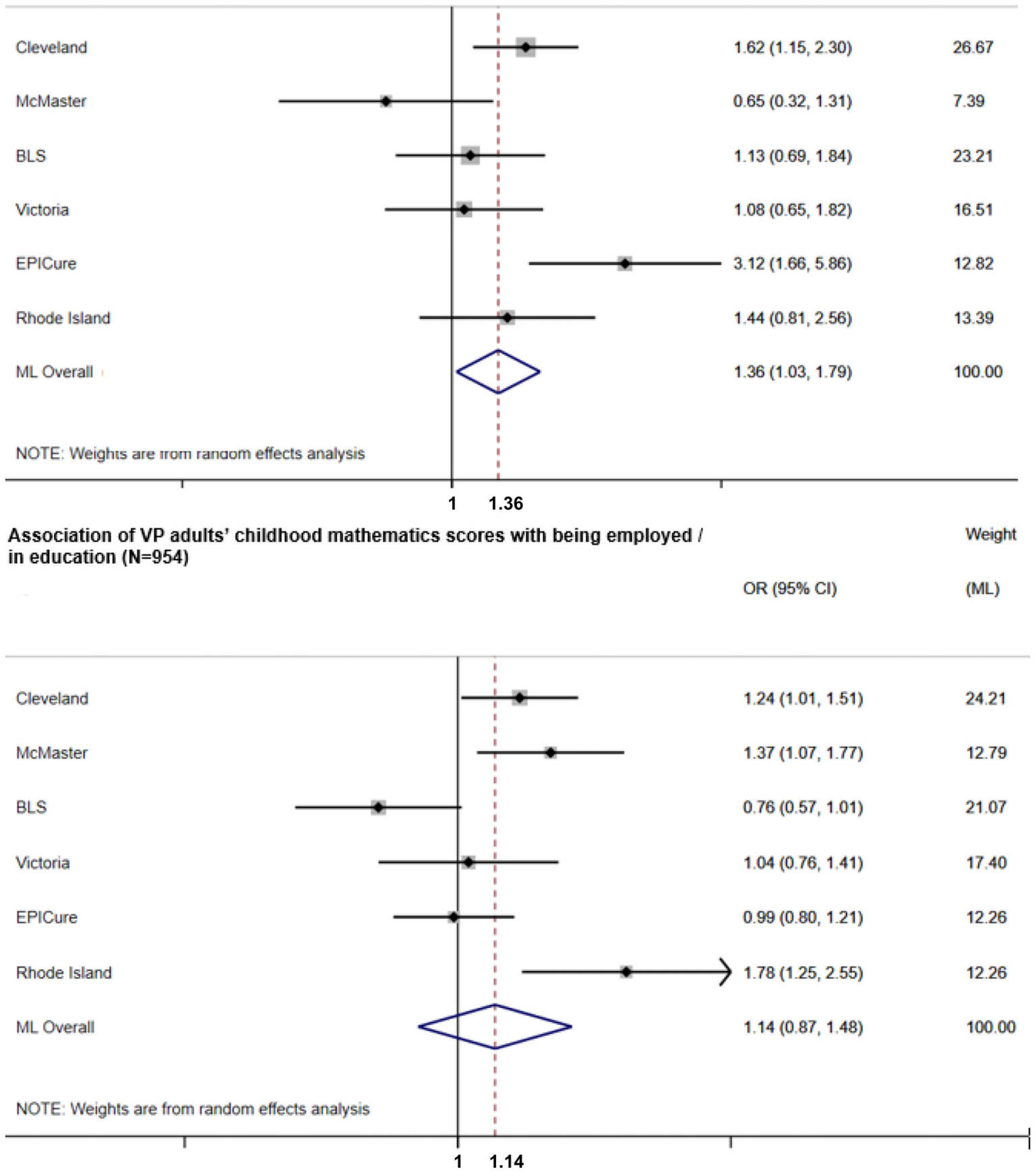

Figure 1: Forest plots showing one-stage individual participant data meta-analysis effects of childhood mathematics scores (odds ratios [0Rs] and 95\% confidence intervals [Cls]) on having attended postsecondary education and being employed/in education in young adulthood. Weights reflect individual study $n$ while accounting for within-study variability and between-study variance. BLS, Bavarian Longitudinal Study; ML, maximum likelihood.

between mathematics performance and being employed or in education in young adulthood. The random effects of mathematics on attending postsecondary education and on being employed or in education were both significant, indicating substantial heterogeneity between study cohorts with regard to the relationship of mathematics with adult 
outcomes. Over and above the effects of mathematics, childhood IQ was independently associated with attending any postsecondary education and being employed or in education. Moreover, females born very preterm and those with higher educated mothers at birth were more likely to attend postsecondary education.

It is important to highlight that this study did not investigate effects of very preterm birth as has traditionally been done in similar meta-analyses. The cohort-specific contemporaneous control data were only used to standardize childhood test scores. With regard to the other variables in the mixed effects models, adults born very preterm who had been born to higher educated mothers had 29\% higher odds of attending postsecondary education, as previously indicated in other studies. ${ }^{10,39}$ The current findings confirm that educational and employment opportunities are enhanced with birth to higher educated mothers, no matter whether in Australia, Europe, or North America. Females born very preterm were twice as likely than males born very preterm to attend postsecondary education. This confirmation that males born very preterm have lower educational attainment than females across these different industrialized societies is important, and, in keeping with previous findings, ${ }^{26,28,29}$ suggests that males born very preterm may benefit from screening and targeted educational support. More research is needed to investigate why males born very preterm may do particularly poorly in education. Although not novel findings, the cross-national and temporal consistency of effects of maternal education and child sex found here may warrant renewed consideration for how early follow-up services and educational policies could support equal opportunities for all members of society. Moreover, our finding of heterogeneity between study cohorts with regard to the relationship of mathematics with adult outcomes may be further investigated by future studies. For instance, it may be worth assessing whether specific educational supports or therapies provided to some cohorts, or individuals within cohorts, might explain this variation and thereby point towards novel interventions.

Our models did not show fixed effects of gestational age at birth. However, variations in adult outcomes according to gestation may have been restricted by the limited range in gestation, mediated by functional childhood indicators such as IQ and mathematics performance, and they may also have been masked by the random effects of cohort membership, since each study cohort had applied different recruitment and sampling criteria, causing wide variations in gestation and birthweight between cohorts (Table 1). $3,33,40,44,46,50$ Accordingly, Table 2 shows a significant random effect of gestation, indicating variation between cohorts in the relationship between gestational age and postsecondary education. Sensitivity analyses excluding EPICure study data also suggested that the association between mathematics performance and postsecondary education varied by gestational age, being stronger among participants born extremely preterm, whose average childhood performance may also have been comparably lower compared with term-born peers due to their birth on the lower extreme of the gestational age spectrum (see Table 1).

\section{Strengths and limitations}

Our IPD meta-analysis confirms our ability to predict lifecourse outcomes into early adulthood across different very preterm cohorts sampled across different birth epochs, neonatal health care services, and education systems. Using pooled IPD provided a large sample size and allowed better adjustment for confounding bias than a standard metaanalysis. Data harmonization and analysis protocols returned stable and reliable models that accounted for the heterogeneity between cohorts. In the future, we support recommendations to harmonize follow-up instruments ${ }^{51}$ to further facilitate comparative studies.

For reasons of ecological validity and data distribution we decided to use postsecondary education (i.e., having attended college after graduation from secondary school) as the dependent variable for educational attainment. Access to higher education has been found to represent an excellent indicator of attainment and economic success in adults born preterm. ${ }^{10}$ Although education data were recoded using International Standard Classification of Education levels, ${ }^{49}$ some structural differences between education systems may not be fully eliminated. For instance, graduating from high school and choosing the respective pathway into higher education may have a higher threshold in Germany and the UK than in North America, in part because alternative professional apprenticeship qualification pathways may be more typical for large parts of the population in Europe. For instance, according to $2020 \mathrm{OECD}$ data, ${ }^{52}$ population rates of postsecondary educational attainment among 25- to 34years-olds differ between Germany (35\%) and Australia (54\%) and the USA (52\%). Respectively, the values in Table 1 should be interpreted with these country-specific differences in mind. Nevertheless, our main results focus on associations between variables, not descriptive rates of outcomes. Moreover, national differences in elementary school education (e.g., regular age at formal school entry, rates of delayed school entry, and rates of inclusion of children with disabilities [often very preterm] into mainstream schooling) ${ }^{17,53}$ and differences in ages at assessments may have confounded the distribution of variables included in our models. In addition, the childhood assessment was administered at age 11 years in the EPICure cohort, and at age 8 years in the other five cohorts, which may have affected cohort participants' average performance in comparison to their age-matched controls. Indeed, our sensitivity analysis confirmed a slight variation in findings when excluding EPICure participants. At the time of the adult assessment, some cohorts' participants were still in secondary education and were excluded, therefore we had a slightly lower sample size for that dependent variable. In addition, data collection for the young adult assessments was conducted between ages 19 to 29 years, before some participants had fully completed their postsecondary education and established career trajectories. Accordingly, our assessment of the role of 
childhood mathematics performance for the socioeconomic success of adults born very preterm is limited to young adulthood; the findings require replication in older populations with participants in their 30s or 40s.

There is some risk of bias. Our literature search did not identify eligible cohorts beyond the APIC network, which was likely because of the complexity and strict criteria of our research question and resulting search term combinations, we did not search grey literature or trials in progress data. The search was performed in English only. Although unlikely, eligible cohorts whose data were simply not published within a life-course analysis framework may exist. Each of the co-authors of this current study were involved in at least one of the original cohort publications, and a formal investigation of the original data for risk of bias issues was not performed. Finally, despite spanning three continents, all cohorts included were from high-income countries, a limitation of most very preterm life-course studies. ${ }^{15,54}$

\section{CONCLUSIONS}

Among infants born very preterm, performance in mathematics in childhood represents an independent functional indicator of attending postsecondary education, but it is not associated with being employed or in full-time education in early adulthood. IQ was strongly and consistently associated with both postsecondary education and employment/education in young adulthood. Despite substantial variations between cohorts (i.e., world regions and birth epochs), males born very preterm were consistently at higher risk than females born very preterm of not attending postsecondary education, as were infants born very preterm to mothers of lower educational background. These findings have implications for the planning of long-term follow-up and support after very preterm birth.

\section{ACKNOWLEDGEMENTS}

We would like to sincerely thank the APIC community for their feedback on the initial data harmonization and analysis strategy. Special thanks are due to Prof Eero Kajantie and Dr Petteri Hovi for allowing access to the Cleveland Study data set after Prof Maureen Hack's passing, and for sharing their harmonization documentation and legal agreement templates. JJ was supported by grant JA 1913/2-2 from the German Research Foundation. DW and PB were supported by an EU Horizon 2020 grant 733280 (RECAP-preterm) and DW by the New Opportunities for Research Funding Agency Co-operation in Europe, Dynamics of Inequality Across the Life-course Program (grant number: 462-16040). The EPICure studies were funded by the Medical Research Council (MR/N024869/1). NM receives funding from the NIHR Biomedical Research Centre at University College London/University College London Hospitals. The McMaster Study was supported by grant No. ESPM85-201, Hospital for Sick Children Foundation, Toronto, Ontario and a Team Grant (2009H00529) from the Canadian Institutes of Health Research awarded to LS and SS. The Rhode Island cohort studies were funded by the National Institutes of Health, National Institute of Nursing Research (Grant \# R01 NR 003695-01; R01 NR003695-14). PA was supported by the Australian National Health and Medical Research Council Investigator Grant (\#1176077). JC was supported by Australian Medical Research Future Fund Career Development Fellowship (\#1141354). The Victorian Infant Collaborative Study studies were funded by the Australian NHMRC (\#1104300, \#491246).

\section{DATA AVAILABILITY STATEMENT}

The aggregated data that support the findings of this study are available on request from the corresponding author. The individual data points are not available due to privacy or ethical restrictions of individual study cohorts.

\section{SUPPORTING INFORMATION}

The following additional material may be found online:

Table S1: Childhood standardized mathematics and IQ tests, and control group criteria by cohort

Table S2: Associations of childhood mathematics scores with attending postsecondary education and being employed/in education in young adulthood in six very preterm cohorts, without adjusting for confounding variables

Table S3: Associations of childhood mathematics scores and other covariates with attending postsecondary education and being employed/in education in young adulthood in six very preterm cohorts, excluding participants with intellectual impairment

\section{REFERENCES}

1. Chawanpaiboon S, Vogel JP, Moller A-B, Lumbiganon P, Petzold M, Hogan D, et al. Global, regional, and national estimates of levels of preterm birth in 2014: a systematic review and modelling analysis. Lancet Glob Health. 2019;7(1):e37-e46.

2. Ruegger C, Hegglin M, Adams M, Bucher HU, Swiss Neonatal N. Population based trends in mortality, morbidity and treatment for very preterm- and very low birth weight infants over 12years. BMC Pediatrics. 2012;12:17

3. Cheong JL, Anderson PJ, Burnett AC, Roberts G, Davis N, Hickey L, et al. Changing neurodevelopment

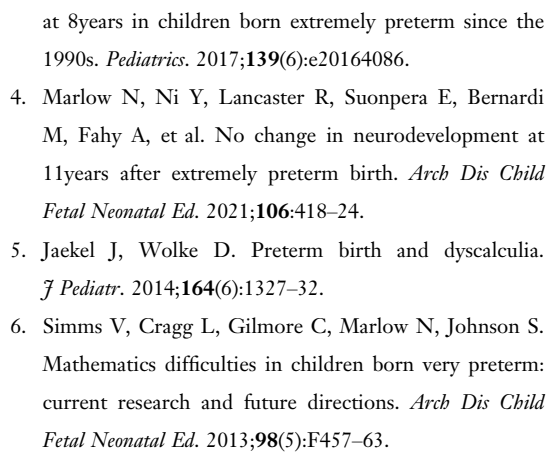

at 8 years in children born extremely preterm since the 1990s. Pediatrics. 2017;139(6):e20164086.

4. Marlow N, Ni Y, Lancaster R, Suonpera E, Bernardi $M$, Fahy A, et al. No change in neurodevelopment at 11 years after extremely preterm birth. Arch Dis Child Fetal Neonatal Ed. 2021;106:418-24.

5. Jaekel J, Wolke D. Preterm birth and dyscalculia. 7 Pediatr. 2014;164(6):1327-32.

6. Simms V, Cragg L, Gilmore C, Marlow N, Johnson S. Mathematics difficulties in children born very preterm: current research and future directions. Arch Dis Child Fetal Neonatal Ed. 2013;98(5):F457-63.

\footnotetext{
7. Simms V, Gilmore C, Cragg L, Clayton S, Marlow N, Johnson S. Nature and origins of mathematics difficulties in very preterm children: a different etiology than developmental dyscalculia. Pediatr Res. 2015;77(2):38995.

8. Taylor HG, Espy KA, Anderson PJ. Mathematics deficiencies in children with very low birth weight or very preterm birth. Dev Disabil Res Rev. 2009;15(1):52-9.

9. Litt JS, Gerry Taylor H, Margevicius S, Schluchter M, Andreias L, Hack M. Academic achievement of adolescents born with extremely low birth weight. Acta Paediatr. 2012;101(12):1240-5.
} 
10. Bilgin A, Mendonca M, Wolke D. Preterm birth/low birth weight and markers reflective of wealth in adulthood: a meta-analysis. Pediatrics. 2018;142(1):e20173625.

11. Doyle LW, Anderson PJ. Adult outcome of extremely preterm infants. Pediatrics. 2010;126(2):342-51.

12. Breeman LD, Jaekel J, Baumann N, Bartmann P, Wolke D. Preterm cognitive function into adulthood. Pediatrics. 2015;136(3):415-23.

13. Linsell L, Johnson S, Wolke D, O'Reilly H, Morris JK, Kurinczuk JJ, et al. Cognitive trajectories from infancy to early adulthood following birth before 26weeks of gestation: a prospective, population-based cohort study. Arch Dis Child. 2018;103(4):363-70.

14. Saigal S, Day KL, Van Lieshout RJ, Schmidt LA, Morrison KM, Boyle MH. Health, wealth, social integration, and sexuality of extremely low-birth-weight prematurely born adults in the fourth decade of life. 7AMA Pediatr. 2016;170(7):678-86.

15. Wolke D, Johnson S, Mendonça M. The life course consequences of very preterm birth. Ann Rev Dev Psychol. 2019;1(1):69-92.

16. Saigal S, van Ouden L, Wolke D, Hoult L, Paneth N, Streiner DL, et al. School-age outcomes in children who were extremely low birth weight from four international population-based cohorts. Pediatrics. 2003;112(4):943-50.

17. Wolke D, Strauss VY-C, Johnson S, Gilmore C, Marlow N, Jaekel J. Universal gestational age effects on cognitive and basic mathematic processing: 2 cohorts in 2 countries. 7 Pediatr. 2015;166(6):1410-6.e2.

18. Simms V, Gilmore CK, Cragg L, Marlow N, Wolke D, Johnson S. Mathematics difficulties in extremely preterm children: evidence of a specific deficit in basic mathematics processing. Pediatr Res. 2013;73(2):236-44.

19. Crawford C, Cribb J. Reading and maths skills at age 10 and earnings in later life: a brief analysis using the British Cohort Study. Institue for Fiscal Studies and Centre for Analysis of Youth Transitions (CAYT) 2013.

20. Ritchie SJ, Bates TC. Enduring links from childhood mathematics and reading achievement to adult socioeconomic status. Psychol Sci. 2013;24(7):1301-8.

21. Jaekel J, Baumann N, Wolke D. Effects of gestational age at birth on cognitive performance: a function of $\operatorname{cog}$ nitive workload demands. PLoS One. 2013;8(5):e65219.

22. Poulsen G, Wolke D, Kurinczuk JJ, Boyle EM, Field $\mathrm{D}$, Alfirevic $Z$, et al. Gestational age and cognitive ability in early childhood: a population-based cohort study. Paediatr Perinat Epidemiol. 2013;27(4):371-9.

23. Breeman LD, Jaekel J, Baumann N, Bartmann P, Wolke D. Neonatal predictors of cognitive ability in adults born very preterm: a prospective cohort study. Dev Med Child Neurol. 2017;59(5):477-83.

24. Johnson S, Strauss V, Gilmore C, Jaekel J, Marlow N, Wolke D. Learning disabilities among extremely preterm children without neurosensory impairment:
Comorbidity, neuropsychological profiles and scholastic outcomes. Early Hum Dev. 2016;103:69-75.

25. Jaekel J, Baumann N, Bartmann P, Wolke D. General cognitive but not mathematic abilities predict very preterm and healthy term born adults' wealth. PloS One. 2019;14(3):e0212789.

26. Duncan GJ, Ziol-Guest KM, Kalil A. Early-childhood poverty and adult attainment, behavior, and health. Child Dev. 2010;81(1):306-25.

27. Basten M, Jaekel J, Johnson S, Gilmore C, Wolke D. Preterm birth and adult wealth: mathematics skills count. Psychol Sci. 2015;26(10):1608-19.

28. Steinmayr R, Spinath B. Sex differences in school achievement: what are the roles of personality and achievement motivation? Eur 7 Pers. 2008;22(3):185209.

29. Heinonen K, Eriksson JG, Kajantie E, Pesonen A-K, Barker DJ, Osmond C, et al. Late-preterm birth and lifetime socioeconomic attainments: The Helsinki Birth Cohort Study. Pediatrics. 2013;132(4):647-55.

30. Jastak S, Wilkinson GS. Wide range achievement test revised. 3rd edn. The Psychological Corporation; 1984.

31. Wechsler D. Wechsler Intelligence Scale for Children, 3rd edn. The Psychological Corporation; 1991.

32. Cheong JLY, Wark JD, Cheung MM, Irving L, Burnett $\mathrm{AC}$, Lee $\mathrm{KJ}$, et al. Impact of extreme prematurity or extreme low birth weight on young adult health and well-being: the Victorian Infant Collaborative Study (VICS) 1991-1992 Longitudinal Cohort study protocol. BM7 Open. 2019;9(5):e030345.

33. Saigal S, Szatmari P, Rosenbaum P, Campbell D, King S. Cognitive abilities and school performance of extremely low birth weight children and matched term control children at age 8 years: a regional study. 7 Pediatr. 1991;118(5):751-60.

34. Wechsler D. Wechsler intelligence scale for childrenrevised. Psychological Corporation; 1974.

35. Dobson KG, Ferro MA, Boyle MH, Schmidt LA, Saigal S, Van Lieshout RJ. Socioeconomic attainment of extremely low birth weight survivors: the role of early cognition. Pediatrics. 2017;139(3):e20162545.

36. Riegel K, Ohrt B, Wolke D, Österlund K. Die Entwicklung gefährdet geborener Kinder bis zum fünften Lebensjahr. Die Arvo Ylppoe NeugeborenenNachfolgestudie in Südbayern und Südfinnland. Ferdinand Enke Verlag; 1995:337.

37. Wolke D, Leon-Villagra J. Mathematiktest für Grundschulkinder. Munich: Bavarian Longitudinal Study; 1993.

38. Kaufman AS, Kaufman N. Kaufman assessment battery for children. American Guidance Service; 1983.

39. Eryigit Madzwamuse S, Baumann N, Jaekel J, Bartmann P, Wolke D. Neuro-cognitive performance of very preterm or very low birth weight adults at 26 years. 7 Child Psychol Psychiatry. 2015;56(8):857-64.
40. Marlow N, Wolke D, Bracewell MA, Samara M. Neurologic and developmental disability at six years of age after extremely preterm birth. N Engl 7 Med. 2005;352 (1):9-19.

41. Johnson S, Hennessy E, Smith R, Trikic R, Wolke D, Marlow N. Academic attainment and special educational needs in extremely preterm children at 11 years of age: the EPICure study. Arch Dis Child Fetal Neonatal Ed. 2009;94(4):F283-9.

42. Wechsler D. Wechsler Individual Achievement Test, 2nd edition. Harcourt Assessment; 2004.

43. O'Reilly H, Johnson S, Ni Y, Wolke D, Marlow N. Neuropsychological outcomes at 19 years of age following extremely preterm birth. Pediatrics. 2020;145(2): e20192087.

44. Hack M, Flannery DJ, Schluchter M, Cartar L, Borawski E, Klein N. Outcomes in young adulthood for very-low-birth-weight infants. N Engl f Med. 2002;346 (3):149-57.

45. Woodcock RW, Johnson MB. Woodcock-Johnson Psycho-Educational Battery-Revised. Riverside; 1989.

46. McGrath M, Sullivan M. Birth weight, neonatal morbidities, and school age outcomes in full-term and preterm infants. Issues Compr Pediatr Nurs. 2002;25(4):23154.

47. Sullivan MC, McGrath MM. Perinatal morbidity, mild motor delay, and later school outcomes. Dev Med Child Neurol. 2003;45(2):104-12.

48. Sullivan MC, Winchester SB, Msall ME. Prematurity and cardiovascular risk at early adulthood. Child Care Health Dev. 2019;45(1):71-8.

49. UNESCO. International Standard Classification of Education. ISCED 20112012.

50. Wolke D, Meyer R. Cognitive status, language attainment, and prereading skills of 6-year-old very preterm children and their peers: the Bavarian Longitudinal Study. Dev Med Child Neurol. 1999;41:94-109.

51. Kajantie E, Johnson S, Heinonen K, Anderson PJ, Wolke D, Evensen KAI, et al. Common Core Assessments in follow-up studies of adults born pretermRecommendation of the Adults Born Preterm International Collaboration. Paediatr Perinat Epidemiol. 2021; 35(3):371-87.

52. OECD. Population with tertiary education; 2021. Available from: https://data.oecd.org/eduatt/populationwith-tertiary-education.htm (accessed 23 November 2021).

53. Jaekel J, Strauss VYC, Johnson S, Gilmore C, Wolke D. Delayed school entry and academic performance: a natural experiment. Dev Med Child Neurol. 2015;57 (7):652-9.

54. Jaekel J. The impact of preterm birth on the life course: assessment challenges and future directions. Dev Med Child Neurol. 2020;62:1357. 